\title{
Action, not words
}

\section{Japan is beginning to recognize that the status and treatment of women researchers must change - but it has yet to take decisive action to address the problem.}

$T$ Tar he under-representation of women in Japanese science, particularly at its higher levels, is not exactly news. The latest figures on the problem are nonetheless sobering. According to an annual government report on gender equality published in May, fewer than $12 \%$ of working scientists in Japan are women - the lowest proportion of anyleading industrial nation. Even more strikingly, fewer than $4 \%$ of full university science professors are female.

There are some signs, however, that the issue is at last gaining the recognition it deserves. For example, the dismal statistics in the report provoked a barrage of critical coverage in the Japanese press, which might once have been inclined to ignore the issue.

Japanese institutions have started to publicly acknowledge the problem and set targets to redress it. Backin 2000, the Science Council of Japan, which is the interface between Japan's academic societies and the government, said it would raise the number of women on its 210 -strong central committee to $10 \%$ by 2010 . The number, which had hovered around $1 \%$ before the announcement, crept past $3 \%$ during 2000 and to $6 \%$ in 2003.

A cabinet committee on gender equality, meanwhile, set the target of having $30 \%$ of all 'leading positions' in society - which should include senior researchers - occupied by women by 2020 . A national five-year plan on gender equality, when it is renewed next year, will add the question of women in science to its list of a dozen 'priority objectives.' The Council for Science and Technology Policy, the top science policy body in the government, has also pledged action. According to one official working on the gender issue, "the little voice of women researchers is starting to be heard".

All of this official activity may start to pull more women into science. But even if that happens, too little is being done to address the set of circumstances that keeps them on the lower rungs of the research ladder, and prevents them from building productive and independent careers.

Junior scientists, for example, are usually dependent on fixedterm grants from research agencies that do not take account of maternity leave. Laboratories in universities and elsewhere make little provision for nursery care. They also lack an accessible and
"Laboratories make little provision for nursery care. They also lack an effective body to investigate allegations of discrimination." effective body to investigate allegations of discrimination.

The time is now ripe for the science and education ministry, the universities and the research agencies to put all their fine words into action as they prepare their annual budget requests for submission next month. The Council for Science and Technology Policy will review these requests in the autumn. When it does so, it should consider carefully whether institutions are acting quickly enough to implement Japan's gender-equality objectives. Agencies and institutions that aren't doing so, and prefer to pay lip-service to the issue, need to be made aware that their failure will carry a cost.

\section{Two cheers for the $\mathbf{G 8}$}

\section{World leaders made modest but welcome progress on poverty in Africa and climate change.}

ast week's meeting in Scotland of the Group of Eight leading industrialized nations was preceded by the usual game of raising and lowering expectations by pressure groups and the participants, designed to ensure that the summit could afterwards be pronounced a 'failure' or a 'success'. The London bombings of 7 July were timed to undermine the summit, but in fact had the opposite effect. The aftermath of the terrorist attack tempered criticism of the meeting and allowed the G8 leaders to receive credit for at least attempting to tackle the two main items on their host Tony Blair's agenda: Africa and climate change.

The meeting will not, of course, end African poverty but, on balance, the UK prime minister can be reasonably satisfied with its contribution to that end. No less an authority than Bob Geldof, the Irish rock star who organized a series of concerts and demonstrations to focus public attention on the summit, said afterwards that he gave the meeting " 10 out of $10^{\text {" }}$ for its commitment to increased aid for Africa, and ${ }^{\alpha} 8$ out of $10^{n}$ for its provisions on debt relief. Few development economists would be as generous as Geldof, but the commitments made at the summit did exceed early expectations.

The G8's recognition that development projects must be Africanled is particularly welcome, as is its pledge to tie aid to good governance. In this regard, the Global Fund to Fight AIDS, Tuberculosis and Malaria, which the summit communiqué agreed to refinance, has been leading the way: most of its support goes to countries that show determined and sustained commitment to a project, and to get more money they have to meet agreed milestones.

The communiqué did not say much directly about the role of science and technology in African development. But scientific staff and infrastructure are needed to make policy and tackle disease, develop agriculture and promote an educated workforce. Africa's leaders have recognized this themselves and, through the New Partnership for Africa's Development (NEPAD), are developing plans for science on the continent. It is to be hoped that some of the aid money committed during the meeting will be used to support these plans.

With regard to climate change, the pattern to emerge from the summit is altogether less impressive. Ignoring a plea by the G8 
members' scientific academies, the communiqué declined to acknowledge explicitly either the serious threat posed by climate change, or the established facts regarding the central role of fossilfuel consumption in that threat. It contains some very soft language about the need to "slow and, as the science justifies, stop and then reverse the growth of greenhouse gases".

It is little wonder that environmental groups, and some scientific institutions such as Britain's Royal Society, have roundly denounced the climate communiqué. But even in this verbose document, optimists can unearth some evidence of progress. All of its signatories, including US President George Bush, acknowledge that fossil fuels "contribute in large part to increases in greenhouse gases associated with the warming of our Earth's surface" . Some people are interpreting this deliberately vague sentence as evidence that Bush is slowly accepting the science of climate change.

The communiqué also reaffirmed the role of the United Nations Framework Convention on Climate Change (UNFCCC) in responding to climate change. It now falls to the next Conference of the Parties to the UNFCCC in Montreal this autumn to use any political tail wind from the summit to come up with a plan that looks beyond 2012 and will follow on from the Kyoto Protocol. If that plan contains more flexible, market-led approaches towards promoting cleaner energy supplies and industry than did the Kyoto Protocol, and incorporates meaningful participation by developing countries, there is a chance that the United States will eventually rejoin the process.

By the 2008 G8 meeting in Japan, when the leaders are committed to revisiting the climate-change issue, it is even possible that the United States will be in the throes of a presidential campaign between two main candidates who are each committed to taking the issue seriously.

In the end, the communiqué from the summit meeting may have contained rather fewer "The communiqué declined to acknowledge the serious threat posed by climate change or the central role of fossil-fuel consumption in that threat."

concrete steps than Blair hoped for when he set out the agenda. But at least it succeeded in elevating the public profile of two of the most important questions that face humanity.

\section{Diversionary tactics}

\section{A map in a Nature supplement is being used to divert debate about science funding in China.}

T here are good scientists from the island of Taiwan. There are good scientists from mainland China. When Nature publishes a paper from Chinese scientists, whether they come from one or the other is not an issue. And whether Taiwan is an independent country - certainly an important and sensitive matter - is not an issue on which Nature takes a stand.

It is unfortunate, therefore, that the significance of a map of China in a Nature publication has been blown out of proportion and, reportedly, used by some bureaucrats to block several of the supplement's commentaries from wide dissemination.

The map appeared last November in China Voices II, a Chinese language supplement devoted to science and science policy in China (and a successor to a similar supplement that was well received a year previously). The map did not show Taiwan. Many Chinese who saw the map admit that they

"Issues of science funding such as these are universal, controversial, and benefit from open, critically minded discussion." did not even notice the omission, but some immediately claimed that it was a deliberate attempt to portray Taiwan as an independent state.

When Nature specifies Taiwan's status, we follow the convention set by the United Nations and describe it either as a 'region' or an 'island. The map was originally inserted for decorative purposes, and so in recognition of the acute sensitivity in China of the issue of Taiwanese independence, and in view of our neutral position on the question, Nature promptly rounded up all the copies of the supplement and destroyed them (a couple of hundred had already been distributed). We then printed several thousand copies of a new version - with no map.

And yet the distribution of the revised supplement continues to be obstructed. At a February session of China's National Congress, officials from the Ministry of Science and Technology were reportedly running about with copies of the original version claiming that Nature was in a conspiracy to rip Taiwan from the mainland.

Why have the ministry's bureaucrats reacted in this way? In reality, sources say, they were upset by the content of some of the essays, which were critical of China's science policy. They have sought to use the map controversy to divert attention from the real issues.

The spirit of the supplement was to support the healthy development of science in China, and all articles were written by scientists working in China or intimate with it. Some articles in the supplement are critical. One takes China to task for ploughing too much of its science budget into large, long-term, applied research projects at the expense of smaller-scale, basic science in which, the author argues, individual creativity can flower. Another, more pointed still, cites the lack of peer review in most grant allocation and calls on the Ministry of Science and Technology to surrender control of its sciencebudget to organizations better able to distribute the funds where they are needed most. (In fact, the office of the Minister of Science and Technology turned down an offer to write a commentary for the supplement.)

Issues of science funding such as these are universal, controversial, and benefit from open, critically minded discussion in many countries. The supplement (copies of which can be obtained from chinavoices@naturejpn.com) was intended to foster such debate within China and in the worldwide Chinese community. But such discussion should not be diverted by a false characterization of Nature's intentions. 